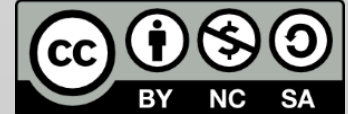

(C) Copyright: The Authors. This article is issued under the terms of the Creative Commons Attribution NonCommercial Share Alike License, which permits use and redistribution of the work provided that the original author and source are credited, the work is not used for commercial purposes and that any derivative works are made available under the same license terms.

\section{Abortion and Reproductive Justice - The Unfinished Revolution II}

\author{
Ulster University 2-3 June 2016
}

\section{Pam Lowe*}

Address

*Correspondence: p.k.lowe@aston.ac.uk

Abortion and Reproductive Justice - the Unfinished Revolution II is, as the name suggest, the second conference in what is intended to be a bi-annual series. Bringing together academics, activists and the arts, the conference aims not just to be a space of dissemination and networking, but to shine a light on areas of the world that need improved access to abortion services. In June 2016, it was held in Belfast, Northern Ireland. For those who are not aware, the 1967 Abortion which governs the UK mainland did not apply to Northern Ireland. This means that the overwhelming majority of women seeking abortion have to either travel to the UK mainland or buy illegal abortion pills over the internet, risking prosecution and a potential prison sentence. If they choose to travel, despite being part of the National Health Service, Northern Ireland women have to pay for their abortions on the mainland, unlike women in England, Scotland and Wales that are treated for free. Abortion is usually considered a highly controversial issue in Northern Ireland, and so far repeated attempts to change the law have barely made a difference. Hence, the importance of holding a high-profile conference with participants from across the world cannot be overstated. Moreover, since the first conference in the series was held on Prince Edward Island, access to abortion has improved. Participants in Belfast were clearly hoping that this conference will also be a small step in bringing about change in Northern Ireland.

It cannot be overestimated the importance of holding conferences to bring together people working on such a stigmatised issue. Not only is it important to hear about struggles and successes, to make new friends and 
potential future collaborators, being surrounded by others all working in the same, often stigmatised, area refreshes and renews the participants. Overcoming stigma was a major theme of the conference, and whilst this was most often discussed in relation to those seeking or providing abortion, on the sides other areas of stigma were discussed. For example, those of us who work in academia often find our work marginalised in mainstream conferences. Not having to start a conversation or presentation by justifying our feminism and our work on abortion is a liberating in itself. This does not mean to say that there were not disagreements on specific aspects, but the solidarity between (not quite all) the participants was palpable.

In total, 145 delegates from a range of different countries including Australia, Canada, Ireland, Poland, Zimbabwe and the Philippines. They represented academics in different disciplines such as sociology, law, medicine and history as well as activists and artists working in different places across the globe. Alongside traditional presentation sessions, discussion sessions also took place on issues such as developing networks, stigma, activism and counselling. A huge range of issues were covered including papers on religion, legal challenges, medicalisation and migration. A problem most of us experienced was finding it very hard to choose which of the parallel session to attend, and most of us would have wanted to attend them all.

On the first day of the conference, the key note speaker was Marlene Gerber Fried. As many people know, Marlene has been a reproductive rights activist for many years. Alongside her academic work, she has been actively involved in activism including being a board member of the National Network of Abortion Funds. For those without money, organisations that provide grants for abortion procedures and, if necessary, travel costs to access them are an important lifeline for women across the world. Marlene gave a moving speech about the constant battle in the US against the challenges to abortion. She reminded the delegates 
of how just because abortion is legal does not mean you are able to get access to it. Many clinics have closed due to the activities of the antiabortion movement both in harassing staff and patients outside of the clinics and through the introduction of 'TRAP laws', targeted regulation of abortion providers. These seek to reduce access to abortion by introducing unnecessary standards (such as making corridors wide enough so to gurneys can pass each other). Their tactics can also include introducing mandatory waiting periods or making health professionals tell women misinformation about the risk of breast cancer. Yet despite the difficult situation that Marlene was describing, her enthusiasm and humour inspired rather than depressed the audience motivating us all to go further in challenging those that seek to reduce or outlaw women's access.

The second keynote speaker, Sylvia Estrada-Claudio, known as Guy, was equally inspiring on the second day. Guy sees herself more as an activist than an academic and reported on the difficulties that women face in the Philippines. The high level of maternal mortality rates she reported caused by a lack of access to abortion and other reproductive health services were a sobering reminder that reproductive justice is a life and death issue. Guy described the battles that women have had to gain legal rights to contraception and abortion and spoke of how in order to gain rights sometimes it is necessary to focus on evolution rather than revolution. In the Philippines, she argued, they needed to focus on getting women to access to contraception before campaigning for abortion, as the former was more likely to be achieved first and would make a significant difference to women's lives. The Responsible Parenthood and Reproductive Health Act (2012), which sought to give women access to contraception, took about fourteen years to pass and then was subject to challenge through the court system afterwards. Guy reminded the conference of the need for both national and international campaigns to keep the long-term goals of reproductive justice in mind whilst fighting 
different battles and to keep in mind both the universal need and the specific circumstances of women in very different circumstances.

One of the most interesting sessions I attended was a debate over the ethics of research facilitated by Susan Yanow. She raised the question as whether research on how women access abortion in ways that are illegal could jeopardize others ability to do so by publicizing their routes of access. Susan pointed out the number of accounts of women travelling across borders and to the internet sale of the abortion pill. Discussion took place as to how to balance this potential risk with the goal of showing how laws and barriers to access did not prevent abortion but could increase the potential for abortions to be unsafe. Further discussion took place as to how academics, activists and providers needed to better understand the constraints that each other faced in order to facilitate research that is useful to all.

There was one element to the conference that seemed to be more hotly debated than the others. A couple of delegates appeared to be questioning some basic aspects of abortion as an essential service, and when one of them presented a review of selected studies outlining health 'risks' of abortion it raised suspicions about their position, not least because of the outdated evidence that was presented. Later they publically revealed themselves to be anti-abortion activists. The debate amongst the rest of the delegates was to how to deal with this situation. Some people were extremely upset, especially if they had presented data not yet in the public domain, and were concerned about the implications for their research sites and themselves. Others, including myself, felt that whilst the covert nature of their attendance was unfortunate, being exposed to such a huge range of important presentations on all aspects of abortion might lead them to think again about some of the myths and lies perpetuated by anti-choice groups. Whether or not this lead to these particular individuals thinking differently we may never know, but I believe that it is of utmost importance for those of us who research, campaign 
and/or provide abortions to defend women's rights to a wide range of audiences especially those who would seek to reduce them.

Dr Pam Lowe is a senior Lecturer in Sociology and Policy at Aston University. Her research is centred around women's reproductive health, with a particular interest in pregnancy, contraception and parenting. She is currently researching public activism on abortion (with a particular focus on anti-abortion activities outside of clinics) and the sexual health of online sex workers in Birmingham. Her most recent book, Reproductive Health and Maternal Sacrifice: Women, Choice and Responsibility was published by Palgrave in 2016.

\section{To cite this article:}

Lowe, P. (2017). Abortion and Reproductive Justice - The Unfinished Revolution II (Ulster University 2-3 June 2016). Feminist Dissent, (2), 193197. Retrieved from:

http://journals.warwick.ac.uk/index.php/feministdissent/article/view/16/95 